\title{
Unidimensional, non-stationary modeling of a high mountain river in southern Ecuador
}

\author{
Ana Ochoa-Sánchez ${ }^{1,2,3}$ (D), Luis Timbe ${ }^{1,2}$ (D), Angel Vázquez-Patiño ${ }^{1,2,3,4}$ (D), \\ Esteban Samaniego ${ }^{1,2,3}$ (iD)
}

1 Dirección de Investigación de la Universidad de Cuenca, Universidad de Cuenca, Cuenca, Ecuador.

2 Departamento de Recursos Hídricos y Ciencias Ambientales, Universidad de Cuenca, Cuenca, Ecuador.

3 Facultad de Ingeniería, Universidad de Cuenca, Cuenca, Ecuador.

4 Departamento de Ciencias de la Computación, Universidad de Cuenca, Cuenca, Ecuador.

Autora de correspondencia: ochoa.anaelizabeth@gmail.com

Fecha de recepción: 19 de septiembre de 2018 - Fecha de aceptación: 26 de noviembre de 2018

\section{RESUMEN}

Las inundaciones son una causa severa de muertes y pérdidas económicas. Para prevenir, mitigar y reducir los riesgos por inundaciones y sus consecuencias, los modelos hidráulicos permiten el análisis y mapeo de dichas inundaciones. Los resultados de un modelo apropiado, que trabaje en base a condiciones locales, son herramientas valiosas para los gobiernos locales, conduciendo a un manejo sustentable de las llanuras de inundación. Alrededor del mundo, muy pocos ríos de alta montaña han sido modelados; y, debido a su orografía, la escasez de datos presenta una dificultad adicional en su investigación. Tomando en cuenta que todos los modelos unidimensionales asumen que el fondo del río tiene una pendiente pequeña, este estudio evalúa dos modelos unidimensionales ampliamente usados: Mike11 y HEC-RAS, para modelar un río de alta montaña. La mejor configuración del modelo, bajo condiciones topográficamente complejas, y su potencial uso fueron valorados mediante su calibración y validación. Al contrario de los resultados obtenidos para el modelo Mike11, tanto en calibración como en validación, hemos encontrado que el modelo HEC-RAS no es capaz de encontrar una solución estable durante el modelamiento hidrodinámico del río. Este estudio sienta un precedente en cuanto a modelación unidimensional en ríos de alta montaña con escasez de datos.

Palabras clave: modelación de ríos 1D, HEC-RAS, Mike11, ríos de alta montaña, Ecuador.

\section{ABSTRACT}

Floods represent a severe cause of deaths and economic loss. In order to prevent, mitigate, and reduce flood risks and their consequences, hydraulic models allow analysing and mapping floods. The results of an appropriate model that works under local conditions are a valuable tool for local governments leading to sustainable management of floodplains. Around the world, high-mountain rivers have been poorly modelled; their orography and data scarcity present an extra research difficulty. Considering that all one-dimensional models assume that the river bed slope is small, this study evaluated two widely applied one-dimensional models: Mike11 and HEC-RAS, for modelling a high mountain river. Their best configuration under complex topographical conditions and their potential use was assessed by calibration and validation of the models. We found that the HEC-RAS model was not able to define a stable solution of the hydrodynamic modelling of the river, while Mike11 yielded stable results. Furthermore, the validation of the Mike11 model showed good performance. This study sets a precedent in the 1D modelling of high-mountain rivers with data scarcity.

Keywords: 1D river modelling, HEC-RAS, Mike11, high-mountain river, Ecuador.

\section{INTRODUCTION}

Floods represent about $40 \%$ of the natural disasters in the world (Ohl \& Tapsell, 2000) and they killed most people by 2016 (Guha-Sapir, Hoyois, \& Below, 2011). In addition, extraordinary river floods considerably increased the past years involving economic loss (Cunha \& Krajewski, 2011; Dottori et al., 2018; Gilles, Young, \& Schroeder, 2012). Hydraulic models allow analysing and mapping floods that help to prevent, mitigate, and reduce flood risks and their consequences. Different methodologies are useful for flow modelling and the analysis of river flood events, from linear interpolation of water level records (0D) (Apel, Aronica, Kreibich, \&
Thieken, 2009) to complete hydrodynamic onedimensional (1D), two-dimensional (2D), coupled 1D and 2D models (Finaud-Guyot, Delenne, Guinot, \& Llovel, 2011), or even three-dimensional (3D) models (Pender \& Néelz, 2007). Model selection depends on the information required, flow characteristics, and type and scale of the specific application. So far, 1D models are most widely used since they require less information (cross sections and roughness coefficients) to be robust and to provide good quality results when the flow is aligned with the main channel axis of the river (Pender \& Néelz, 2007; Vojinovic $\&$ Seyoum, 2011). Although 2D models are more popular lately due to the increase of the computational capacity and information availability, they have difficulties when 
hydraulic structures need to be included, and their computational demand and requirement of information is still high.

The one-dimensional hydrodynamic models, HEC-RAS and Mike11, are the most widely used for flood events analysis and flood mapping (Alaghmand, Abdullah, Abustan, \& Eslamian, 2012; Andrei, Robert, \& Erika, 2017). The Federal Emergency Management Agency of the US (FEMA) accepts both for this kind of application (FEMA, 2018). These models compute one-dimensional solutions of the Saint-Venart equation. HEC-RAS model is freeware while Mike11 has a commercial license.

All one-dimensional models assume that the river slope is small, which is not the case for high mountain rivers. Therefore, this study identifies the possibility of using onedimensional models for flood modelling of a high mountain river, their best configuration under these topographical conditions, and their potential use. The results of an appropriate model that works under such conditions are a valuable tool for governments leading to sustainable management of floodplains. This study compares the performance of HEC-RAS and Mike11 models and calibrates and evaluates both these models at a high mountain river.

\section{MATERIALS AND METHODS}

\subsection{Study area and data availability}

The river branch of the Quinoas River is located at $E l$ Cajas National Park in the Andean region of Ecuador, geographically defined by $2.7^{\circ}-2.8^{\circ} \mathrm{S}$ and $79.0^{\circ}-79.3^{\circ} \mathrm{W}$
(Fig. 1). The microcatchment area of the river branch studied is approximately $86.5 \mathrm{~km}^{2}$ and its altitudinal range is between 3,000 and 4,400 $\mathrm{m}$ a.s.l. (Fig. 1). The complete Quinuas microcatchment $\left(94 \mathrm{~km}^{2}\right)$ belongs to the subcatchment of the Río Tomebamba $\left(380 \mathrm{~km}^{2}\right)$ and the Paute catchment $\left(6148 \mathrm{~km}^{2}\right)$. The river branch length is $11.4 \mathrm{~km}$ and its slope changes abruptly along the river length with a maximum of $18 \%$, a minimum of $1.5 \%$, and a media of $6 \%$. The main channel bottom consists of gravels, cobbles, and a few boulders, while there are shortgrass pasture floodplains.

Three hydrological stations are situated in strategical locations along the river branch (Fig. 1). Data from Virgen del Cajas (VC) station located upstream and Puente Matadero (PM) station at the downstream of the river constituted the model boundary conditions. Data from Chirimachay $(\mathrm{CH})$ station was used to calibrate and validate the hydraulic model. The water level time series with a 5-minute temporal resolution were checked for homogeneity and outliers. The salt dilution gauging technique applied in the field allowed building rating curves for the three stations. Four events from around a month were selected from one year of data (Table 1). The hydrographs for the boundary conditions during calibration and validation are shown in Figure 2. The microcatchment was divided in seven contribution areas (Fig. 1) that allowed the model to distribute the discharge difference between PM and VC stations along the river.

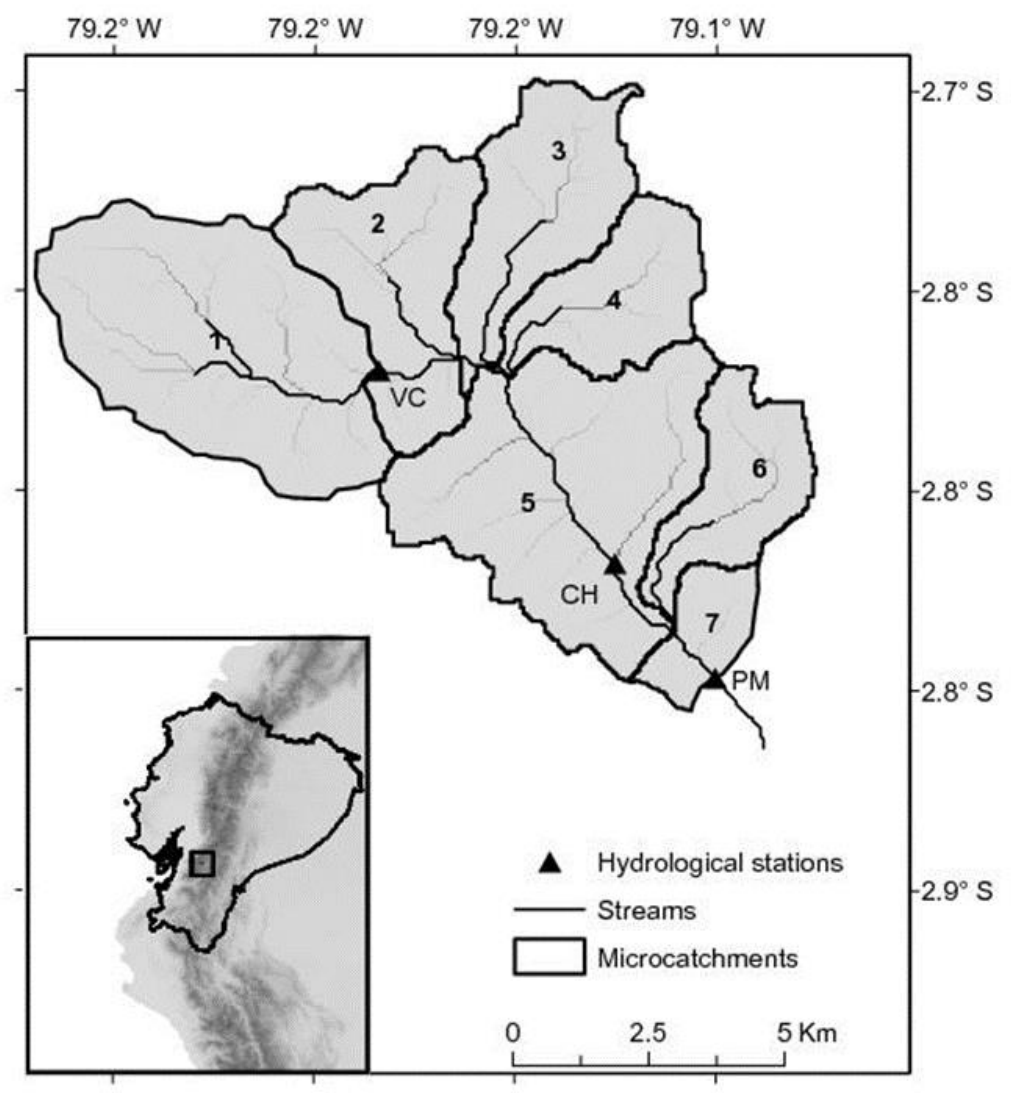

Figure 1. Location of the study area and hydrological stations. Subdivision of the microcatchment into areas of contribution to the river branch. 
Table 1. Events for calibration and validation of the Mike 11 model.

\begin{tabular}{lllllc}
\hline & \multicolumn{2}{c}{ Event duration } & \multicolumn{3}{c}{ Maximum discharge registered $\left[\mathrm{m}^{3} / \mathrm{s}\right]$} \\
\cline { 2 - 6 } & Initial date & Final date & VC & CH & PM \\
\hline Hydrograph 1 & $07 / 05 / 2014$ 00:00 & $17 / 05 / 201423: 00$ & 1.3 & 7.3 & 11.2 \\
Hydrograph 2 & 05/10/2014 00:00 & $31 / 10 / 2014$ 11:00 & 1.7 & 7.5 & 35.0 \\
Hydrograph 3 & $13 / 07 / 2014$ 00:00 & $23 / 07 / 201409: 00$ & 0.3 & 3.4 & 4.0 \\
Hydrograph 4 & $18 / 05 / 2014$ 00:00 & $18 / 06 / 201400: 00$ & 0.9 & 5.2 & 8.9 \\
\hline
\end{tabular}

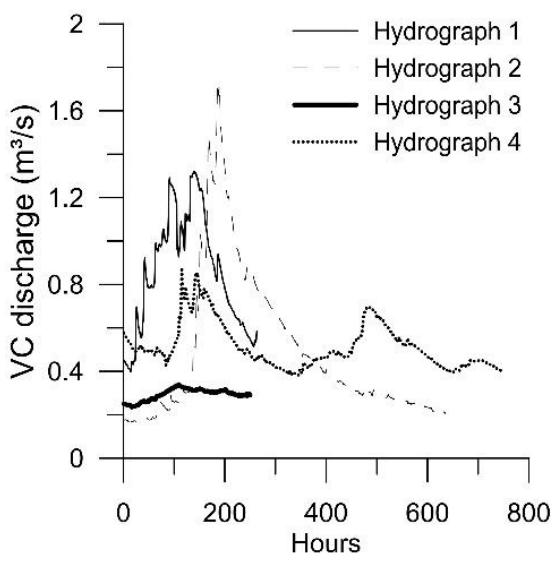

(a)

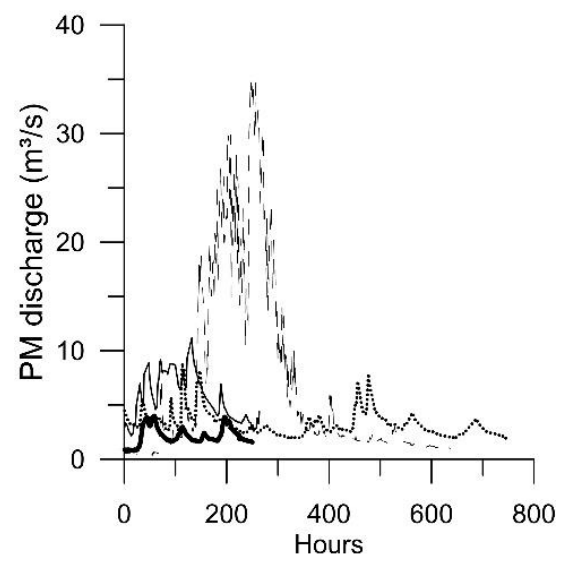

(b)

Figure 2. Events for calibration and evaluation of the model at (a) Virgen del Cajas (VC) station and (b) Puente Matadero (PM) station.

\section{$\underline{\text { Hydraulic models }}$}

In this study, the models HEC-RAS (Version 4.1) and Mike11 (Version 2007) were configured to perform the one-dimensional unsteady flow in the Quinuas high mountain river reach. The model's configuration, calibration, and evaluation analysis aimed to represent the river hydraulics under the condition of steep slopes. Since models normally assume that the slope is small and supercritical flow was expected, the modifications introduced in both these models for the modelling of a mixed flow regime (MFR: subcritical and supercritical flow) are specified in the following.

\section{Mike11 model}

The hydrodynamic module (HD) in Mike11 uses an implicit differential scheme developed by Abbott \& Ionescu (1967) for non-permanent flow calculation in rivers and estuaries. This module can describe subcritical and supercritical flow through a numerical scheme that follows the local flow conditions in time and space. The computational scheme is suitable for vertical homogeneous flow from steep rivers to tidal influenced estuaries (DHI, 2017). Stability conditions depend particularly on the relationship between the time step and grid spacing. Mike11 allows selecting between three flow descriptions: dynamic wave, kinematic wave, and diffusive wave. The first one can be chosen between high order fully dynamic wave and dynamic wave only. It describes flow considering all the terms of the SaintVenant equation (local acceleration, convective acceleration, pressure force, gravity force, and friction force). The kinematic wave assumes a balance between the friction and gravity terms and, consequently, does not account backwater effects. The diffusive wave ignores inertial terms (DHI, 2017). Mike11 dynamic wave approach assumes that the water is incompressible and homogeneous, the bottom-slope is small, the wavelengths are large compared to the water depth, and the flow is subcritical (DHI, 2007). For supercritical flow, a reduced momentum equation is applied which neglects the convective acceleration term of the Saint Venant equation. For the transition of sub-critical to supercritical flow, a gradual reduction of the momentum term is introduced for smooth description. Also, the differential equation is upstream gradually centred as the influence of the upstream condition increases. Details on the suppression of convective acceleration are in section 1.35.1 of the Mike 11 Reference Manual (DHI, 2007).

\section{HEC-RAS model}

The non-stationary flow component of the HEC-RAS model is able of calculating one-dimensional flow of natural and artificial channels. The model solves continuity and momentum equations with a solution scheme, primarily developed for subcritical flow, that was adapted from the UNET model by Barkau (1996), and it is known as the four-point scheme, box scheme, or Preissman scheme. Drastic changes in the cross sections' properties, wave characteristics, and complex hydraulic structures affect the stability of the scheme (Brunner, 2010). Since the release of Version 3.1, the model can perform MFR (subcritical, supercritical, hydraulic jumps, and drawdowns). The so-called Local Partial Inertia (LPI) solution technique approach is used to carry out the MFR analysis (Fread, 1996). As stated by Brunner (2010), when this option is turned on, the program monitors the Froude number at all cross-sections each time step. As the Froude number gets close to 1.0, the program automatically reduces the magnitude of the inertial terms in the momentum equation since this increases the model's stability. Otherwise, for Froude numbers equal to or greater than 1.0, the inertial terms are completely zeroed 
out and the model is essentially reduced to a diffusion wave routing procedure (Brunner, 2010).

\section{Models configuration}

During field survey, cross sections were measured every $25 \mathrm{~m}$ and nearer at the presence of meanders. Geometry was processed in CivilCad $®$ and imported afterwards in HEC-RAS and Mike11. Open boundary conditions corresponded to a hydrograph at VC (upstream) and water level time series at PM (downstream). Also, hydrographs as point source inflows were configured in the cases of the microcatchments number 2, 3, 4, and 6 (Fig. 1); and as distributed source inflows at the microcatchments number 5 and 7 (Fig. 1). Initial conditions corresponded to the first discharge in each hydrograph at VC. Simulations time intervals were 0.5 seconds to guarantee model stability. Model's output temporal resolution was one hour.

\subsection{Model calibration}

Three events were used for model calibration: Hydrographs 1, 2, and 3 (Fig. 2 and Table 1). Fifty simulations were run for every hydrograph. The friction coefficient was one of the most important parameters when calibrating the one-dimensional models, given the absence along the river reach of hydraulic structures (i.e., weirs). Manning's coefficient $(n)$ represents friction and can be approximated by three methods: field surveys, estimations in the literature, and value adjustments (Vidal, Moisan, Faure, \& Dartus, 2007). Moreover, $n$ should be calibrated based on observed and simulated water levels. In this study, we considered field survey results, however, those values where far from the more realistic values available in literature.

Table 2. Manning's coefficient ranges for the Quinuas River.

\begin{tabular}{|c|c|c|}
\hline & Reach stations [m] & $n$ \\
\hline Main channel & $11,400-0$ & $0.025-0.050$ \\
\hline \multirow{2}{*}{ Floodplains } & $\begin{array}{l}0-2,948.31 \text { and } \\
7,847.88-9,693.67\end{array}$ & $0.040-0.080$ \\
\hline & $\begin{array}{l}2962.06-7828.08 \text { and } \\
9,742.18-11,400\end{array}$ & $0.110-0.600$ \\
\hline
\end{tabular}

During calibration, cross section files were created by changing Manning values randomly (uniform distribution) from a theoretical range according to the channel and floodplains material of the river (Table 2). At Chirimachay station (CH in Fig. 1), water levels from the simulations were compared to the observations through the mean error (ME), the mean square error (MSE), the bias percentage (pbias), the Nash-Sutcliffe model efficiency coefficient (NSE), the Kling-Gupta efficiency (KGE), and the volumetric efficiency (VE). The first coefficient was used to measure the average systematic difference between the modelled and observed water levels. The MSE was used since it is built up on two terms: the first corresponds to $\mathrm{ME}$ and the second measures the variance of the random error after bias correction. The NSE is dimensionless and a scaled version of the MSE. NSE does not depend highly on the water level magnitude, an advantage over ME or MSE. The last two coefficients were developed by Gupta, Kling, Yilmaz, \& Martinez (2009) and Criss \& Winston (2008), respectively, to cope with some problems of the
NSE like its overemphasis on large flows relative to other measurements. KGE ranges from -Inf to 1 and VE ranges from 0 to 1 ; the closer to one, the more accurate the model is for both coefficients. All the metrics were calculated with the hydroGOF R package. Details on the formulation of each index can be consulted at Zambrano-Bigiarini, (2017). The simulation with the lowest ME, MSE, and pbias and the highest NSE, KGE, and VE was defined as the best result possible during calibration and thus their Manning's coefficients were chosen to evaluate the model afterwards. Since model results change in function of the change in input parameters, it is useful to understand model's dependence on the information from which the model is built. This analysis increases the confidence level of the model and its predictions by comprehending the behaviour of the model, its parameters, and applicability. The Manning's coefficients used during calibration lead to fifty simulations per event that were represented as a range of hydrographs that were plot against observations in $\mathrm{CH}$ to show the change in the model's results when bed and floodplain resistance were changed.

\subsection{Model performance evaluation}

Hydrograph 4 (Fig. 2) was compared with model simulation results at $\mathrm{CH}$, using the same statistic coefficients explained before. At this stage, evaluation need to be completed by a graphical method (Willems, 2011). WETSPRO tool (Willems, 2009) was used to analyse events characteristics in a time series, such as high flows, cumulative values representation, and prediction capacity of the model.

\section{RESULTS AND DISCUSSION}

\subsection{Mike11 vs. HEC-RAS modelling}

Mike11 and HEC-RAS modelling of the $11.4 \mathrm{~km}$ of the Quinuas river was conducted for historical events. Figure 3 shows the models results at the most downstream station (PM) in comparison with the water level time series observations (11/10/2013 00:00 - 14/11/2013 00:00). Mike11 yielded a hydrograph coherent with the water level variations observed in the field (Fig. 3a) while HEC-RAS instability issues were notorious (Fig. 3b). Usually, increasing the number of cross sections in steep slopes and decreasing the time step, corrects instability but it was not the case for this HEC-RAS simulation where almost all flow values were negative and high flow variations were present (Fig. 3b). The current simulation was run with and without MFR, and mixed flow options (exponent for Froude number reduction factor $m$ and Froude number threshold for eliminating acceleration terms) were modified. However, instability showed in Figure 3b remained. Figure 4 shows the Froude numbers obtained with the HEC-RAS simulation. Results clearly reveal that along all the $11.4 \mathrm{~km}$ of the river, Froude numbers were completely out of range. In steep slopes, Froude numbers are expected to be higher than 1 but Figure 4 shows values up to 1,100 even when outliers were not plot. When HECRAS finds Froude numbers higher than 1, the inertial terms of the Saint-Venant equation are completely zeroed out and the model is reduced to a diffusion wave routing procedure (Brunner, 2010). This did not allow the model to find stable results. 


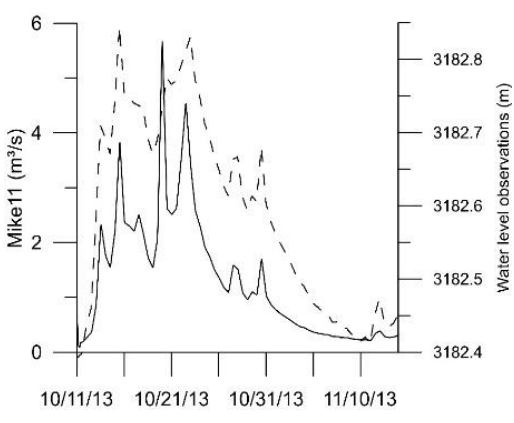

(a)

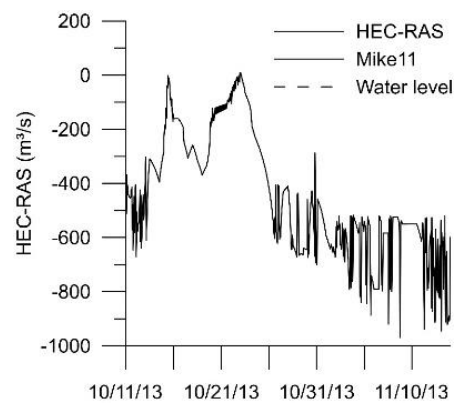

(b)

Figure 3. Modelled and observed hydrographs at the downstream PM station of the river.

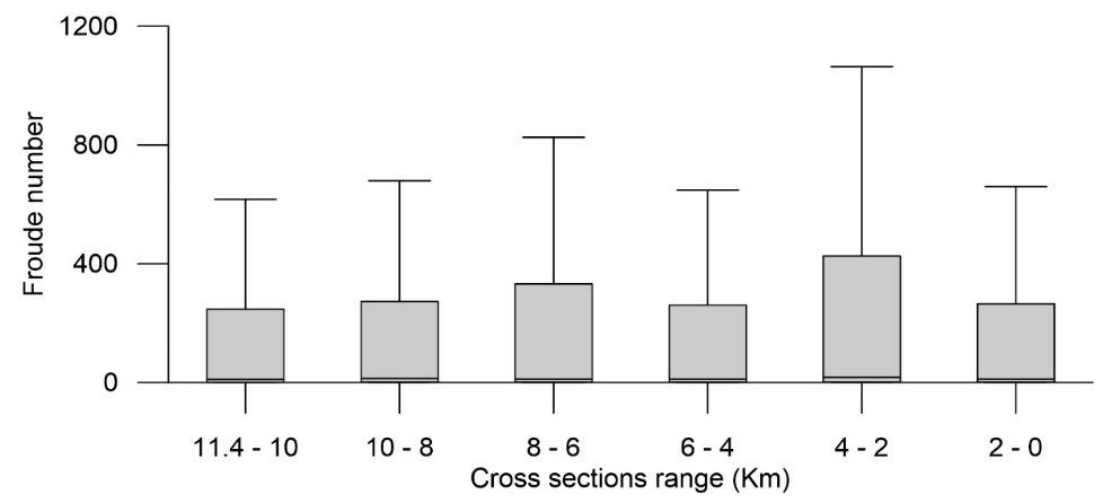

Figure 4. Froude numbers boxplots at cross sections ranges. Boxplots interquartile ranges correspond to 1.5 and outliers are not shown.

Table 3. Mean error (ME), mean squared error (MSE), bias percentage (pbias), Nash-Sutcliffe coefficient of efficiency (NSE), Kling-Gupta coefficient (KGE), and volumetric efficiency (VE) of calibration and validation events.

\begin{tabular}{llllllll}
\hline & 1 & ME $[\mathrm{m}]$ & MSE $\left[\mathrm{m}^{2}\right]$ & pbias [\%] & NSE & KGE & VE \\
& Most efficient sim. & -0.01 & 0.00 & -0.6 & 0.82 & 0.91 & 0.98 \\
& Least efficient sim. & 0.29 & 0.09 & 24.8 & -18.62 & -0.05 & 0.75 \\
\cline { 2 - 8 } Calibration & 2 & & & & & & \\
events & Most efficient sim. & 0.04 & 0.03 & 3.6 & -1.64 & -0.35 & 0.90 \\
& Least efficient sim. & 0.32 & 0.23 & 30.5 & -22.99 & -2.48 & 0.68 \\
\cline { 2 - 8 } & 3 & & & & & & \\
& Most efficient sim. & -0.01 & 0.00 & -0.9 & 0.72 & 0.56 & 0.98 \\
& Least efficient sim. & -0.35 & 0.12 & -34.5 & -77.97 & 0.39 & 0.65 \\
\hline $\begin{array}{l}\text { Validation } \\
\text { event }\end{array}$ & 4 & & & & & & \\
& Evaluation sim. & 0.0004 & 0.0003 & 0.00 & 0.81 & 0.73 & 0.99 \\
\hline
\end{tabular}

Mike11 results at Chirimachay station were stable, including the rating curve and discharge time series (not shown). MIKE11 gives the user the opportunity to choose between three flow descriptions: dynamic wave, kinematic wave, and diffusive wave (DHI, 2007). For the dynamic wave approach, it gives two choices: dynamic wave and high order dynamic wave. The first attempt to model the Quinuas river was done using the kinematic wave approach since this flow description is recommended for steep slopes (DHI, 2007). The assumption of a balance between friction and gravity means that the kinematic wave approach cannot simulate backwater effects; and thus, this description is appropriate for relatively steep rivers without backwater effects (DHI, 2007). However, the model configured with the kinematic wave method was unstable. The remaining flow descriptions were used as well; however, stable conditions were only reached with the high order dynamic wave approach using a time step of 0.5 seconds.

Bennett, Walton, Dickerson, \& Howard (2004) states that the computational method for determining channel roughness is one such difference between HEC-RAS and Mike11 and they provide a conversion between the two coefficients in order to find similar results with the models. However, in this study, the roughness coefficient was not the cause of the dissimilarity since HEC-RAS was run with multiple coefficients and the instability remained. Stability was only achieved when the high order dynamic wave option in Mike 11 was run. During supercritical flow, Mike11 used the Saint-Venant equation without the convective term while HEC-RAS eliminated the local and the convective acceleration terms. Additionally, Mike11 modifies the scheme during supercritical conditions. These differences resulted in a stable Mike11 simulation. 
Therefore, Mike 11 software was chosen for the river branch unsteady flow calibration and validation stages.

\subsection{Mike11 model calibration}

Fifty simulations with different Manning's coefficients were run in Mike11 for each of the three hydrographs used for calibration. Water levels were compared, and one simulation has the minimum ME, MSE, and pbias and the maximum KGE, VE and NSE; while other simulation has the maximum ME, MSE, and pbias and the minimum KGE, VE and NSE (Table 3). Figure 5 shows changes in the model's results due to the changes in the Manning's coefficient. The $n$ values from the most efficient model were chosen during this stage as having better statistical results (Table 4).

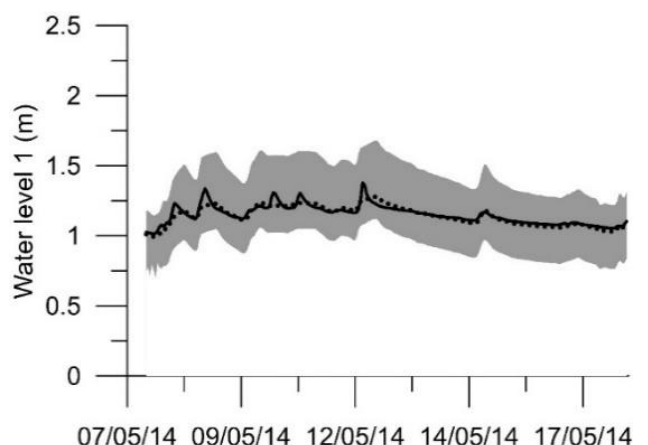

(a)

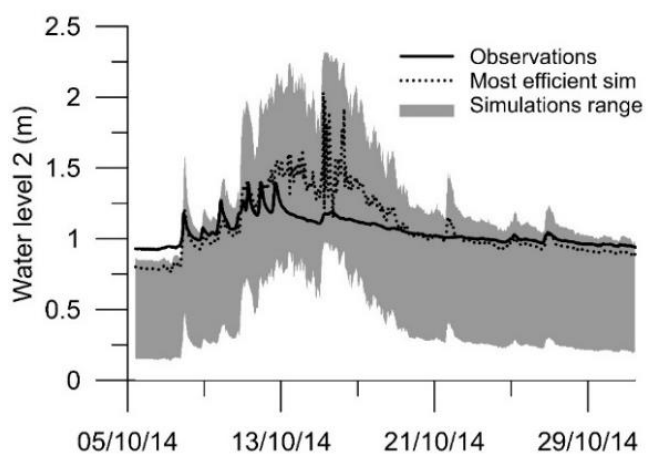

(b)

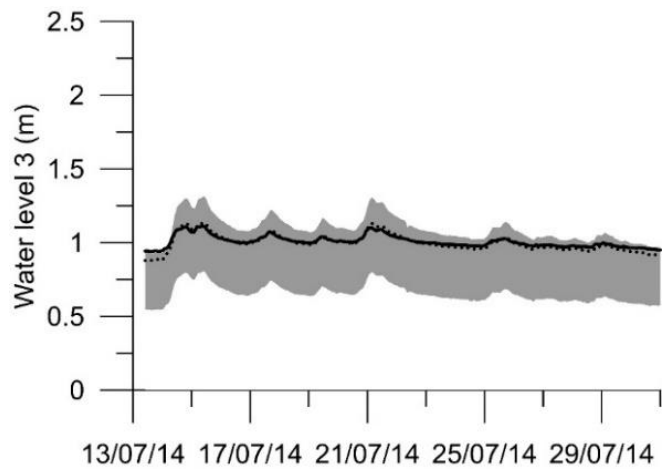

(c)

Figure 5. Modelled and observed water levels at $\mathrm{CH}$ station during calibration stage: (a) Observed Water level 1 corresponds to Hydrograph 1 in Figure 2; (b) Observed Water level 2 corresponds to Hydrograph 2 in Figure 2; (c) Observed Water level 3 corresponds to Hydrograph 3 in Figure 2.
The ME, MSE and pbias of the best simulation showed a low biased model, especially for low and medium flows (water level 1 and water level 3, Table 3). Also, for those water level magnitudes, the NSE, KGE and VE indexes were more than 0.6 and even 0.99 , showing a good agreement between model and observations. However, the second event coefficients showed a model that overestimated water levels in $30 \%$ and had a poor performance, with negative values of NSE and KGE (Table 3 and Fig. 5b). These results are understandable given that the high peaks in the second event gauged at PM (Fig. 2) were very difficult to measure due to the high turbulence involved.

Table 4. Manning's coefficients ( $n$ ) values chosen during calibration of the Mike 11 model.

\begin{tabular}{|c|c|c|}
\hline & Reach stations (m) & $n$ \\
\hline Main channel & $11,400-0$ & 0.032 \\
\hline \multirow{2}{*}{ Floodplains } & $\begin{array}{l}0-2,948.31 \text { and } \\
7,847.88-9,693.67\end{array}$ & 0.040 \\
\hline & $\begin{array}{l}2,962.06-7,828.08 \text { and } \\
9,742.18-11,400\end{array}$ & 0.593 \\
\hline
\end{tabular}

\subsection{Mike11 model performance evaluation}

Statistical results of the model performance evaluation are shown in Table 4. The errors showed good performance of the model in all the calculated coefficients. The unbiased model has an NSE of 0.81 (Table 3). The KGE value during validation, showed that the model estimates agreed in $73 \%$ with the observed values when the three aspects of validation: correlation, bias, and variability were decomposed (Gupta et al., 2009). A value of VE equal to the one, in Table 3, means that $99 \%$ of water was delivered in a proper time (Criss \& Winston, 2008). Low and high flows were treated equally when evaluating the model with VE. Until now, evaluation corresponded to an average of high and low flows altogether. Therefore, a complementary graphical analysis for validation follows.

Mike11 flows were plotted against observations (see Fig. 6) showing underestimation of the low and high flows but a notorious correlation. Baseflow was estimated with the WETSPRO tool and shown in Figure 6.

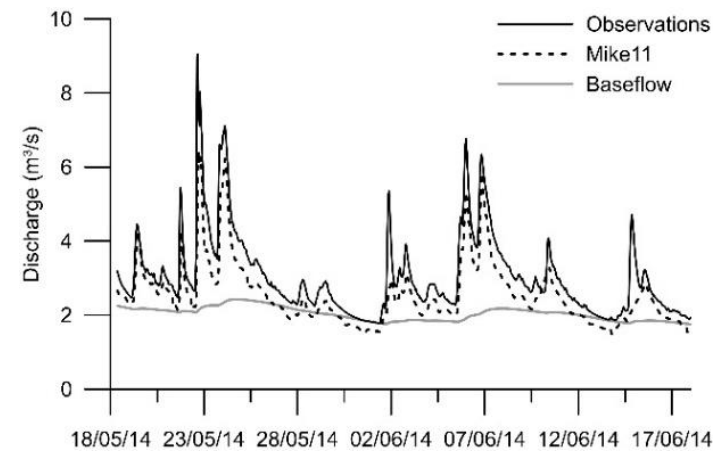

Figure 6. Modelled, observed and baseflow time series at $\mathrm{CH}$ station during evaluation stage.

This approach allowed finding peaks over a threshold (also called events) that are useful when peaks occur in a different time step on the observed and modelled time series. Afterwards, transformation of the events was needed to reach independency of the residuals on the flow values (homoscedastic residuals). Figure 7 shows the 
transformed simulated against observed events together with the mean deviation, bisector, and standard deviation.

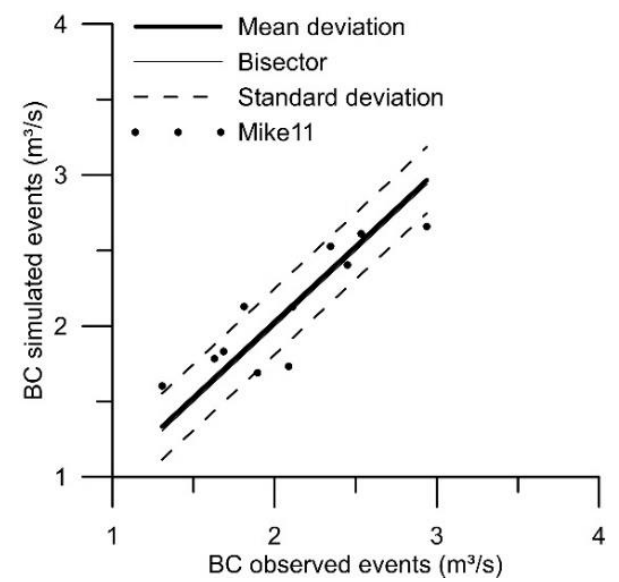

Figure 7. Observed and modelled peak flows at $\mathrm{CH}$ station during evaluation stage.

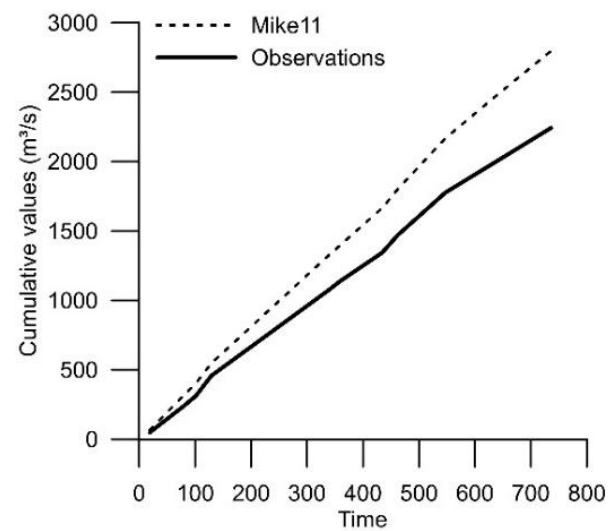

Figure 8. Observed and modelled cumulative values at $\mathrm{CH}$ station during evaluation stage.

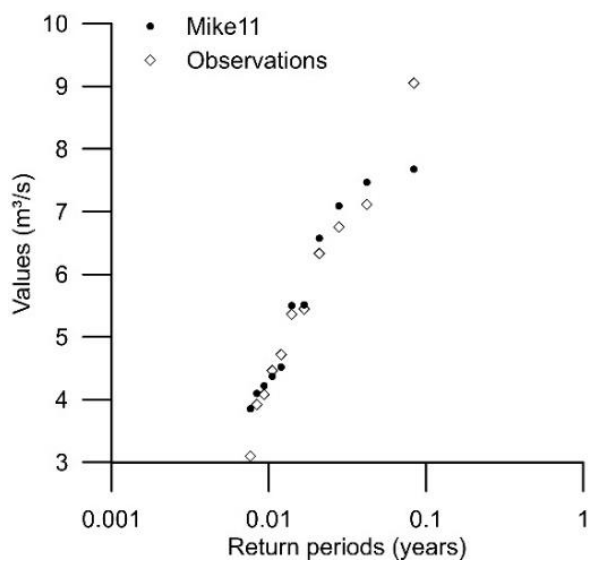

Figure 9. Observed and modelled events vs return period at $\mathrm{CH}$ station during evaluation stage.

Displacement of the bisector from the mean and scattering of the points usually shows when a model is biased. In this case, such displacement does not exist since we have an unbiased model. In addition, the river is displayed as a reservoir in Figure 8, where Mike 11 underestimated cumulative values. In conclusion, Figure 9 depicts the predictable capacity of the model by plotting the events against their return period. Most of the selected events were well estimated by the model, and only a peak of around $9 \mathrm{~m}^{3} / \mathrm{s}$ was underestimated. The latter is not a finalconclusion due to data scarcity, but it is under consideration since monitoring is ongoing.

\section{CONCLUSIONS}

We modelled a river branch of the high mountain Quinuas river with the Mike11 and the HEC-RAS models. Model implementation of both models showed similar complexity, so does their operation. However, in this study, the Mike11 model provided stable results, while the HEC-RAS model's instability remained after several configurations were attempted. Reasons for this discrepancy were found in the treatment that the models give to supercritical flows. When the Froude number is equal or exceeds 1 , Mike 11 calculates the Saint-Venant equation excluding the convective acceleration term, while HEC-RAS eliminates the local and the convective acceleration terms. Additionally, Mike11 modifies the scheme during supercritical conditions for a smooth transition from subcritical to supercritical flow. Therefore, only Mike11 could be used for calibration and evaluation of the Quinuas river branch.

During calibration of the Mike11 model, a range of Manning's coefficient ( $n$ ) values was determined representing theoretically bed resistance in the channel and floodplains. We simulated fifty randomly chosen values for each event of the three selected hydrographs. Results revealed that the model was sensitive to the bed resistance of the channel and floodplains. Calibration allowed choosing the optimum values of $n$.

During model performance evaluation, we determined that the model was able to estimate water levels with almost no bias $\left(\mathrm{ME}=0.0004 \mathrm{~m}, \mathrm{MSE}=0.0003 \mathrm{~m}^{2}\right)$ and an NSE of 0.81 . Evaluation concludes that the unbiased model has a high predictive capability, especially at low and medium flows. This model could be useful in the future to implement flood warning systems in the Andean region, a region characterized for having steep slope rivers.

\section{ACKNOWLEDGMENTS}

This research was funded by the DIUC (Research Directorate of the University of Cuenca) via the project "Desempeño y fiabilidad de modelos hidráulicos unidimensionales para la modelación de inundaciones en ríos de montaña".

\section{REFERENCES}

Abbott, M., \& Ionescu, F. (1967). On the numerical computation of nearly horizontal flows. Journal of Hydraulic Research, 5(2), 97-117.

Alaghmand, S., Abdullah, R., Abustan, I., \& Eslamian, S. (2012). Comparison between capabilities of HEC-RAS and MIKE11 hydraulic models in river flood risk modelling (a case study of Sungai Kayu Ara River basin, Malaysia). International Journal of Hydrology 
Science and Technology, 2(3), 270-291. http://doi.org/10.1504/IJHST.2012.049187

Andrei, A., Robert, B., \& Erika, B. (2017). Numerical limitations of $1 D$ hydraulic models using MIKE11 or HEC-RAS software - Case study of Baraolt River, Romania. In: IOP Conference Series: Materials Science and Engineering. http://doi.org/10.1088/1757899X/245/7/072010

Apel, H., Aronica, G., Kreibich, H., \& Thieken, A. (2009). Flood risk analyses - how detailed do we need to be? Natural Hazards, 49(1), 79-98.

Barkau, R. (1996). UNET: One-dimensional unsteady flow through a full network of open channels. User's manual. California. Retrieved from http://oai.dtic.mil/oai/oai?verb=getRecord\&metadataPr efix $=$ html\&identifier $=$ ADA315684

Bennett, T. H., Walton, R., Dickerson, P. D., \& Howard, J. W. (2004). Comparison of HEC-RAS and MIKE11 unsteady flow modeling for the Tillamook Valley. In: Critical Transitions in Water and Environmental Resources Management (pp. 1-8). ASCE. Retrieved from http://cedb.asce.org/cgi/WWWdisplay.cgi?142251

Brunner, G. (2010). HEC-RAS, River analysis system. Hydraulic reference manual. Version 4.1. Davis, CA: U.S. Army Corps of Engineers. Retrieved from http://www.hec.usace.army.mil/ software/hecras/documentation/hec-ras_4.1_reference_manual.pdf

Criss, R. E., \& Winston, W. E. (2008). Do Nash values have value? Discussion and alternate proposals. Hydrological Processes, 22(14), 2723-2725. http://doi.org/10.1002/hyp.7072

Cunha, L., \& Krajewski, W. (2011). A framework for flood risk assessment under nonstationary conditions or in the absence of historical data. Journal of Flood Risk Management, 4(1), 3-22.

DHI. (2007). Mike 11. A modelling system for rivers and channels. Reference manual. Horsholm, Denmark: Danish Hydraulic Institute

DHI. (2017). MIKE 2017 Service Pack 2. Horsholm, Denmark: Danish Hydraulic Institute. Available at https://www.mikepoweredbydhi.com/download/mike2017

Dottori, F., Szewczyk, W., Ciscar, J.-C., Zhao, F., Alfieri, L., Hirabayashi, Y., ... Feyen, L. (2018). Increased human and economic losses from river flooding with anthropogenic warming. Nature Climate Change, $8(9)$, 781-786. http://doi.org/10.1038/s41558-018-0257-z

FEMA. (2018). Hydraulic numerical models meeting the minimum requirement of national flood insurance program. Retrieved from https://www.fema.gov/hydraulic-numerical-modelsmeeting-minimum-requirement-national-floodinsurance-program
Finaud-Guyot, P., Delenne, C., Guinot, V., \& Llovel, C. (2011). 1D-2D coupling for river flow modeling. Comptes Rendus - Mécanique, 339(4), 226-234. http://doi.org/10.1016/j.crme.2011.02.001

Gilles, D., Young, N., \& Schroeder, H. (2012). Inundation mapping initiatives of the Iowa Flood Center: Statewide coverage and detailed urban flooding analysis. Water, 4(1), 85-106.

Guha-Sapir, D., Hoyois, P., \& Below, R. (2011). Annual disaster statistical review 2010: The numbers and trends. Brussels, Belgium: Centre for Research on the Epidemiology of Disasters (CRED), Université Catholique de Louvain. Available at cred.be/sites/default/files/ADSR_2010.pdf

Gupta, H. V, Kling, H., Yilmaz, K. K., \& Martinez, G. F. (2009). Decomposition of the mean squared error and NSE performance criteria: Implications for improving hydrological modelling. Journal of Hydrology, 377, 8091.

Ohl, C. A., \& Tapsell, S. (2000). Flooding and human health. BMJ (Clinical Research Ed.), 321(7270), 11678. https://doi.org/10.1136/bmj.321.7270.1167

Pender, G., \& Néelz, S. (2007). Use of computer models of flood inundation to facilitate communication in flood risk management. Environmental Hazards, 7(2), 106114

Vidal, J.-P., Moisan, S., Faure, J.-B., \& Dartus, D. (2007). River model calibration, from guidelines to operational support tools. Environmental Modelling \& Software, 22(11), 1628-1640. http://doi.org/10.1016/j.envsoft.2006.12.003

Vojinovic, Z., \& Seyoum, S. (2011). Effects of model schematisation, geometry and parameter values on urban flood modelling. Water Science \& Technology, 63(3), 462-467.

Willems, P. (2009). A time series tool to support the multi-criteria performance evaluation of rainfall-runoff models. Environmental Modelling \& Software, 24(3), 311-321. http://doi.org/10.1016/j.envsoft.2008.09.005

Willems, P. (2011). Modelling guidelines for water engineering. Chapter 4. Model calibration and validation. Leuven, Belgium: Katholieke Universiteit Leuven, Faculty of Engineering.

Zambrano-Bigiarini, M. (2017). hydroGOF R package. Available at: http://hzambran.github.io/hydroGOF/ 